\title{
Technology-Aided Programs to Support Positive Verbal and Physical Engagement in Persons with Moderate or Severe Alzheimer's Disease
}

\author{
Giulio E. Lancioni ${ }^{1 *}$, Nirbhay N. Singh ${ }^{2}$, Mark F. O'Reilly ${ }^{3}$, Jeff Sigafoos ${ }^{4}$, Fiora D'Amico ${ }^{5}$, \\ Caterina Renna ${ }^{6}$ and Katia Pinto $^{7}$ \\ ${ }^{1}$ Department of Neuroscience and Sense Organs, University of Bari, Bari, Italy, ${ }^{2}$ Medical College of Georgia, Augusta \\ University, Augusta, GA, USA, ${ }^{3}$ Department of Special Education, University of Texas at Austin, Austin, TX, USA, ${ }^{4}$ School \\ of Education, Victoria University of Wellington, Wellington, New Zealand, ${ }^{5}$ S. Raffaele Medical Care Center, Alberobello, Italy, \\ ${ }^{6}$ Domus Maxima Care Center, Casamassima, Italy, ${ }^{7}$ Alzheimer Center, Bisceglie, Italy
}

\section{OPEN ACCESS}

Edited by: Wai Kwong Tang,

The Chinese University of Hong Kong, Hong Kong

Reviewed by: Francesca Morganti, University of Bergamo, Italy Aurel Popa-Wagner, University of Medicine Rostock,

Germany

*Correspondence:

Giulio E. Lancioni giulio.lancioni@uniba.it

Received: 25 November 2015 Accepted: 08 April 2016

Published: 21 April 2016

Citation: Lancioni GE, Singh NN, O'Reilly MF Sigafoos J, D'Amico F, Renna C and Pinto K (2016) Technology-Aided Programs to Support Positive Verbal and Physical Engagement in Persons with Moderate or Severe Alzheimer's Disease. Front. Aging Neurosci. 8:87. doi: 10.3389/fnagi.2016.00087
Pilot studies using technology-aided programs to promote verbal reminiscence and mild physical activity (i.e., positive forms of engagement) in persons with moderate or severe Alzheimer's disease have provided promising results (Lancioni et al., 2015a,b). The present two studies were aimed at upgrading and/or extending the assessment of those programs. Specifically, Study 1 upgraded the program for verbal reminiscence and assessed it with eight new participants. The upgraded version automatically monitored the participants' verbal behavior during the sessions, in which photos and brief videos were used to foster verbal reminiscence. Monitoring allowed computer approval and reminders to be consistent with the participants' behavior. Study 2 extended the assessment of the program for promoting mild physical activity with 10 new participants for whom arm-raising responses were targeted. The results of Study 1 showed that the participants' mean percentages of intervals with verbal engagement/reminiscence were below 10 during baseline and control sessions and between above 50 and nearly 80 during the intervention. The results of Study 2 showed that the mean frequencies of arm-raising responses were about or below four and between about 10 and 19 per session during the baseline and the intervention, respectively. The general implications of the aforementioned results and the need for new research in the area were discussed.

Keywords: Alzheimer's disease, reminiscence, computer-aided program, visual cues, reminders, approval, physical exercise, arm raising

\section{INTRODUCTION}

Alzheimer's disease is a neurodegenerative disorder that progressively undermines the intellectual and physical functioning of the persons affected, with an increasing deterioration of their general performance (i.e., from their use of time and money to their management of daily activities, social and verbal behavior and mobility/ambulation; De Leo et al., 2011; Melrose et al., 2011; Ambrose, 2012; Bernick et al., 2012; Soto et al., 2012; Sikkes et al., 2013). At present, it is not possible to prevent the occurrence of the disease or to cure 
it effectively (i.e., to eliminate or minimize its effects; Spalletta et al., 2012; Wilson et al., 2012; Perri et al., 2014). Nonetheless, pharmacological and behavioral intervention strategies exist that may have some impact in slowing down the deterioration process, support adaptive and motor performance, and improve social appearance and mood/participation (Giordano et al., 2010; Ferrero-Arias et al., 2011; Bharwani et al., 2012; Boller et al., 2012; Kim et al., 2012; de Vries, 2013; Schecker et al., 2013; Berk et al., 2014; Kurz and Grimmer, 2014; Tifratene et al., 2014).

Behavioral intervention strategies employed for persons in the moderate and severe stages of the disease have been directed at supporting, among others, daily activities, verbal reminiscence, and mild physical exercise (Lancioni et al., 2010, 2012; CreteNishihata et al., 2012; Serrani Azcurra, 2012; Subramaniam and Woods, 2012; Cavallo et al., 2013; Lazar et al., 2014; Wingbermuehle et al., 2014; Phillips et al., 2015). In each of these intervention areas, technology-aided programs were developed and assessed with promising results. For example, Lancioni et al. (2014b, 2015a) reported encouraging results with a technology-aided program set up to foster positive verbal engagement/reminiscence in persons with moderate Alzheimer's disease. The program relied on the presentation of: (a) images of relevant people/events together with requests to talk about them or a virtual partner asking questions; (b) approval for verbal engagement; and (c) reminders (prompts) to seek new images/questions (see also Yasuda et al., 2009; Kuwahara et al., 2010; Lazar et al., 2014). Different sets of images and questions were used across sessions. Similarly, Lancioni et al. (2015b) reported a positive outcome with a technology-aided program aimed at supporting mild physical exercise (i.e., arm raising or leg-foot movement) in persons with advanced Alzheimer's disease, who had lost their ambulation skills and were sedentary and largely inactive and detached. The program included: (a) preferred stimulation contingent on the target response and (b) verbal reminders in case of no responding.

Although the results obtained with the aforementioned technology-aided programs were quite promising, the evidence available is limited. In fact, a total of 22 participants were involved in the two studies targeting positive verbal engagement/reminiscence, and six participants were involved in the study targeting mild physical exercise (i.e., three used arm raising and three leg-foot movement). Given this situation, additional research efforts seem to be warranted to determine the strength of the data available and conceivably, investigate upgrades of the programs so as to make them more functional and/or respectful of the participants (Barlow et al., 2009; Kazdin, 2011; Godwin et al., 2013; Makel and Plucker, 2014).

The present studies were two such research efforts. Study 1 upgraded the technology-aided program for promoting positive verbal reminiscence and assessed such program with eight new participants (thus representing a systematic replication study; see Kazdin, 2011). The new program version (a) presented images of relevant people/events with requests to talk about them and approval and reminders to seek new images, and (b) monitored the participants' verbal behavior via a voice-detecting sensor
(Lancioni et al., 2014a). Such monitoring allowed computer approval and reminders to be consistent with the participants' behavior (i.e., to occur during and in the absence of verbal engagement, respectively, rather than at preset intervals; see Lancioni et al., 2014b, 2015a). The view was that the use of monitoring would preserve or even strengthen the effectiveness of the original program in fostering positive verbal engagement while increasing the level of respect for the participants and their self-determination (Pierce and Cheney, 2008). Study 2 sought to extend the evidence available on the effectiveness of the technology-aided program designed for promoting mild physical exercise (Lancioni et al., 2015b). Specifically, Study 2 implemented the program with 10 new participants who were involved in an arm-raising exercise, with the aim of determining whether preliminary promising results with this form of exercise could be confirmed in a carefully designed, direct replication effort (Kazdin, 2011).

\section{STUDY 1}

\section{Materials and Methods}

\section{Participants}

The eight participants involved in Study 1 included five females and three males, aged 73-96 $(M=82)$ years, and had a diagnosis of moderate Alzheimer's disease with reported scores on the Mini Mental State Examination (Folstein et al., 1975) ranging from 12 to $18(M=15$; see Table 1$)$. The participants tended to be passive and silent, but were capable of responding to verbal questions and reminders, and of watching photos and videos and talking about them. That is, they possessed the skills needed to use the computer program, seemed comfortable with it, and were at ease wearing the aforementioned voice-detecting sensor, which involved a small throat microphone kept at their larynx with a neckband (see Lancioni et al., 2014a).

The participants attended centers for persons with Alzheimer's disease and other dementias, in which they were involved in self-care (e.g., grooming) and leisure (e.g., listening to music) activities. They could also have fairly long periods of inactivity, with only marginal staff supervision. Those periods of inactivity and general silence were considered detrimental and an intervention strategy to counteract them was viewed as desirable. The use of a simple computer-aided program to help the participants reminisce events of their

TABLE 1 | Participants' characteristics (Study 1).

\begin{tabular}{cccc}
\hline Participant & Sex & Age & MMSE \\
\hline 1 & F & 81 & 18 \\
2 & M & 76 & 14 \\
3 & F & 80 & 16 \\
4 & F & 89 & 14 \\
5 & M & 81 & 12 \\
6 & F & 96 & 17 \\
7 & M & 73 & 13 \\
8 & F & 78 & 14 \\
\hline
\end{tabular}

MMSE stands for Mini Mental State Examination. 
life and increase their positive verbal engagement (as pursued in this study) seemed a practical example of such strategy. Participants had expressed their willingness to be involved in the program and staff and families supported it (Lancioni et al., 2015a). Participants had not been asked to sign a formal consent for their involvement in the study, as they were not considered capable of reading a complex text and/or writing. Families had however provided a written informed consent for such an involvement. The study had been approved by the ethics committee of the Alzheimer Association, Bari, Italy.

\section{Technology}

The technology involved a computer system with screen and sound amplifier, a pressure microswitch, a voice-detecting sensor with throat microphone, and basic software. During intervention sessions, the participant had the pressure microswitch (a push button) in front of him or her and the voice-detecting sensor's microphone (which was activated by any audible vocal emission and was unaffected by environmental noise), kept at his or her larynx with a neckband. The participant sat in front of the computer screen, which showed photos or 5-s video clips of relevant people (including him- or herself) and special places and/or community and family events, such as wedding celebrations (Lancioni et al., 2015a). The computer provided a brief verbal description of the photos and the videos (the last frame of which remained on view like the photos) and asked the participant to talk about them. At intervals of 25-50 s, the computer produced approving vocal sounds/words if the participant was talking. A reminder to press the push button and talk more occurred after 10-20 s of participant's silence/passivity (i.e., no activation of the voice sensor or push button). Activation of the push button caused the computer to present a new photo or video (i.e., as described above). Failure to activate the push button and the voice sensor led the computer to provide additional reminders. About 25-40 photos and videos were selected for the single participants with the help of staff and families for use across sessions.

\section{Setting, Sessions, and Data Recording}

Baseline, intervention, and control sessions were carried out in the centers that the participants attended. Sessions lasted $5 \mathrm{~min}$. Typically, two to four baseline or intervention sessions occurred per day per participant (i.e., sessions were carried out on an individual basis). Control sessions were scattered throughout the intervention phase (see below). Data recording concerned: verbal engagement/reminiscence, microswitch activations, and computer reminders (during intervention sessions), the first two of these measures (during baseline sessions), or the first one of these measures (during control sessions). Microswitch activations and computer reminders were recorded by the computer system in terms of frequency per session. Verbal engagement/reminiscence was recorded by research assistants, who used a time sampling procedure with 10-s intervals, and checked reliability in about $25 \%$ of the sessions (Kazdin, 2001). The percentages of interrater agreement in those sessions (computed by dividing session intervals with agreement by total number of session intervals and multiplying by 100) were within the 80-100 range, with means above 90 for all participants.

\section{Experimental Conditions and Data Analysis}

The program was carried out according to a nonconcurrent multiple baseline design across participants (Barlow et al., 2009). The baseline phase included two or four sessions per participant. The intervention phase included 98 to $147(M=126)$ sessions. Parallel to the intervention phase, the participants received 9-20 $(M=14)$ control sessions. A nonparametric (Kolmogorov-Smirnov) test was used to assess differences in the participants' levels of verbal engagement during the intervention sessions (with the technology) and the baseline and control sessions (in which the technology was inoperative or absent; Siegel and Castellan, 1988). Such a test was employed because of the differing numbers of sessions available to the participants during the study periods (i.e., in line with the research design applied for the study; see Barlow et al., 2009; Kazdin, 2011).

\section{Baseline}

During the baseline sessions, the participant sat in front of the computer screen, which was dark, and had the pressure microswitch and voice sensor whose activations did not produce any effects.

\section{Intervention}

During the intervention sessions, the participant was provided with the computer, pressure microswitch and voice sensor, which worked as described in the Technology section. Prior to the start of the intervention phase, each participant received five to seven practice sessions during which the research assistant helped him or her familiarize with procedural conditions and verbal reminiscence.

\section{Control}

During the control sessions (which epitomized periods of general inactivity; see Participants section), no technology was available. The participants sat with other persons with dementia attending the same context, with only marginal staff supervision.

\section{Results}

Table 2 reports the participants' mean percentages (and percentage ranges) of verbal engagement intervals per session during the baseline and intervention phases of the study. During the baseline sessions, the mean percentages of intervals with verbal engagement/reminiscence were below 10 for all participants. During the intervention sessions, the mean percentages of intervals with verbal engagement/reminiscence ranged from above 50 (Participant 7) to nearly 80 (Participant 2), with the overall mean exceeding 65 . The mean frequencies of microswitch activations were (near) zero during the baseline and varied from about two and a half to about six and a half per session (with an overall mean across participants of about four) during the intervention. The mean frequencies of 
TABLE 2 | Number of sessions, mean percentages of verbal engagement intervals per session, and percentage ranges during baseline and intervention (Study 1).

\begin{tabular}{cccccccc}
\hline & \multicolumn{3}{c}{ Baseline } & & \multicolumn{3}{c}{ Intervention } \\
\cline { 2 - 3 } \cline { 7 - 8 } Participant & Sessions & Means & Ranges & & Sessions & Means & Ranges \\
\hline 1 & 2 & 0 & $0-0$ & & 134 & 65 & $33-83$ \\
2 & 2 & 0 & $0-0$ & & 147 & 79 & $33-90$ \\
3 & 2 & 8 & $7-10$ & & 132 & 72 & $37-87$ \\
4 & 4 & 2 & $0-7$ & & 115 & 74 & $43-90$ \\
5 & 2 & 0 & $0-0$ & & 98 & 68 & $37-80$ \\
6 & 4 & 8 & $3-17$ & & 139 & 60 & $30-77$ \\
7 & 4 & 2 & $0-7$ & & 105 & 53 & $23-73$ \\
8 & 4 & 1 & $0-3$ & & 141 & 63 & $30-83$
\end{tabular}

Percentages are rounded to the nearest full number value.

computer reminders (available only during the intervention sessions) varied from below one to about three per session, with an overall mean across participants of about two. During the control sessions, the participants' mean percentages of intervals with verbal engagement/reminiscence were similar to those recorded during the baseline (i.e., below six). The Kolmogorov-Smirnov test showed that the differences between the participants' levels of verbal engagement during the intervention sessions and during the baseline and control sessions combined were statistically significant $(p<0.01$; Siegel and Castellan, 1988).

\section{STUDY 2}

\section{Materials and Methods}

\section{Participants}

The 10 participants involved in Study 2 included five females and five males, aged 67-95 $(M=82)$ years. They were at the moderate or severe level of Alzheimer's disease, with reported scores on the Mini Mental State Examination (Folstein et al., 1975) of 7 to 14 ( $M=9$; see Table 3), and attended centers for persons with Alzheimer's disease and other dementias. They were sedentary and generally passive, but: (a) could perform arm-raising responses deemed beneficial for their physical condition (Rolland et al., 2008; Eggermont et al., 2010; Hoffmann et al., 2013); (b) responded to computer-emitted

TABLE 3 | Participants' characteristics (Study 2).

\begin{tabular}{lccc}
\hline Participant & Sex & Age & MMSE \\
\hline 1 & F & 90 & 11 \\
2 & F & 67 & 8 \\
3 & F & 88 & 7 \\
4 & M & 78 & 10 \\
5 & M & 76 & 11 \\
6 & F & 84 & 14 \\
7 & M & 90 & 10 \\
8 & M & 68 & 9 \\
9 & M & 84 & 7 \\
10 & F & 95 & 8 \\
\hline
\end{tabular}

MMSE stands for Mini Mental State Examination. verbal reminders concerning those responses; and (c) were interested in environmental stimulation events, such as music and videos. Staff and families supported the use of a technologyaided program for fostering arm movements through preferred stimulation for those movements and reminders. Participants seemed keen to be involved in the program, but were not asked to sign a consent form (see "Study 1" Section). The participants' families had provided a written informed consent for the study, which had been approved by the same ethics committee as Study 1.

\section{Sessions, Responses, Technology, and Stimulation}

Sessions lasted $5 \mathrm{~min}$ and were typically carried out 2-4 times a day, in the centers that the participants attended. Arm raising consisted of the participants moving one or both arms upward. The technology included a microswitch, a computer with sound amplifier, and basic software. The microswitch consisted of a tilt device or a combination of two such devices fixed to the participant's arms (Lancioni et al., 2015b). The computer's use during baseline was limited to recording the arm-raising responses. During the intervention, the computer: (a) delivered a 10-s stimulation after each arm-raising response; (b) presented a verbal reminder to raise the arms after periods of about $15 \mathrm{~s}$ of no response from the start of the session or from the end of a stimulation period; and (c) recorded the arm-raising responses and the reminders (Lancioni et al., 2015b).

The stimulation entailed 10 -s periods of popular songs, religious chants, and prayers or videos of friends and activities, which were considered preferred for the participants based on staff reports and stimulus preference screening. Screening included a minimum of 10 nonconsecutive presentations of brief segments of various stimuli. A stimulus was used during the study if, during screening, two research assistants scored it as effective in producing positive reactions (e.g., orienting, smiling, or comments) in $60 \%$ or more of the presentations.

\section{Experimental Conditions and Data Analysis}

The study was carried out according to a non-concurrent multiple baseline design across participants (Barlow et al., 2009). That is, five participants had two or three baseline sessions while the other five participants had four or five baseline sessions. The baseline was followed by an intervention phase, which included 93 to $140(M=119)$ sessions for eight participants. The other two participants (i.e., Participants 7 and 9) had only 63 and 61 intervention sessions due to departure from the care center and to health problems, respectively. During the sessions, the participants sat in a wheelchair or normal chair. Prior to the start of the sessions, the research assistants guided them to perform the target response. The Kolmogorov-Smirnov test (Siegel and Castellan, 1988) was used to assess differences between the participants' frequencies of arm-raising responses during the intervention sessions and during the baseline sessions (see "Study 1" Section). 
TABLE 4 | Number of sessions, mean frequencies of arm-raising responses per session, and frequency ranges during baseline and intervention (Study 2).

\begin{tabular}{lccccccr}
\hline & \multicolumn{3}{c}{ Baseline } & & \multicolumn{3}{c}{ Intervention } \\
\cline { 2 - 3 } \cline { 7 - 8 } Participant & Sessions & Means & Ranges & & Sessions & Means & Ranges \\
\hline 1 & 4 & 3 & $0-8$ & & 104 & 15 & $9-22$ \\
2 & 5 & 4 & $3-5$ & & 112 & 14 & $9-20$ \\
3 & 5 & 1 & $0-3$ & & 138 & 17 & $11-21$ \\
4 & 3 & 1 & $1-1$ & & 109 & 10 & $5-15$ \\
5 & 5 & 2 & $1-4$ & & 119 & 11 & $8-16$ \\
6 & 5 & 2 & $0-4$ & & 140 & 19 & $15-23$ \\
7 & 3 & 1 & $0-2$ & & 63 & 13 & $6-20$ \\
8 & 3 & 2 & $1-6$ & & 136 & 18 & $14-23$ \\
9 & 2 & 0 & $0-0$ & & 61 & 12 & $7-18$ \\
10 & 2 & 0 & $0-0$ & & 93 & 10 & $9-12$ \\
\hline
\end{tabular}

Frequencies are rounded to the nearest full number value.

\section{Baseline}

During the baseline sessions, the technology was available but no stimulation or reminders occurred.

\section{Intervention}

During the intervention sessions, the technology was in use and worked (i.e., provided stimulation and reminders) as described above. The intervention sessions were preceded by five to eight practice/familiarization sessions (see "Study 1" Section).

\section{Results}

Table 4 reports the participants' mean frequencies (and frequency ranges) of arm-raising responses per session during the baseline and the intervention. During the baseline, the participants' mean frequencies of arm-raising responses per session were between zero and four. During the intervention, the mean frequencies of arm-raising responses per session varied from about 10 (Participants 5 and 10) to about 19 (Participant 6), with an overall mean across participants of about 14 . The mean frequencies of computer reminders varied from below one to about nine per session, with an overall mean across participants of near four. The Kolmogorov-Smirnov test showed that the differences between the baseline and the intervention response frequencies were statistically significant for all participants with $p<0.01$ (Participants 1-8) and $p<0.05$ (Participants 9 and 10; Siegel and Castellan, 1988). The latter $p$ value was due to the fact that Participants 9 and 10 had only two baseline sessions.

\section{DISCUSSION}

Studies 1 and 2 provided new evidence on the usability and effectiveness of computer-aided programs for promoting: (a) positive verbal reminiscence in persons with moderate Alzheimer's disease and (b) mild physical exercise in persons with low moderate or severe levels of Alzheimer's disease, respectively (Astell et al., 2010a,b; Lancioni et al., 2014b, 2015a,b; Lazar et al., 2014; Makel and Plucker, 2014). Study 1 also showed a relatively simple way of upgrading the technology for the verbal reminiscence program compared to the versions originally employed (Lancioni et al., 2015a). In light of this upgrading and the results obtained in the two studies, a number of considerations may be in order.

First, the technology upgrading operated in Study 1, that is, the inclusion of a sensor to monitor the participant's verbal behavior did not alter the basic principles/components of the original program (i.e., presentation of images of relevant persons, events or places, requests to talk about them, approval, and reminders; Lancioni et al., 2015a). In reality, the upgrading served to make the program more consistent with (and respectful of) the participant's behavior by ensuring that: (a) positive comments would be contingent on the participant's verbal engagement and (b) reminders would not occur while the participant was still talking (Noguchi et al., 2013; Robert et al., 2013; König et al., 2015).

Second, preservation of all the basic principles/components of the original program for supporting verbal reminiscence engagement was considered a sufficient condition to expect the new, upgraded program to be at least as effective as the original one. Consistent with this assumption, we (a) did not seek to compare the two program versions and (b) treated the data obtained with the upgraded version as an important expansion of the original evidence about the possibility of supporting verbal reminiscence through a technology-aided program (Kazdin, 2001, 2011; Kennedy, 2005; Barlow et al., 2009). It would be theoretically and practically relevant for future research to investigate whether the impact of such positive verbal engagement can extend beyond the constructive/satisfactory experience of the intervention situation (i.e., beyond the sessions' time and context), and represent a partial and/or temporary form of protection against the inevitable degenerative process caused by the disease (Buchhold et al., 2007; Huang et al., 2009; Chiang et al., 2010; Saczynski et al., 2014; Freret et al., 2015; Bechard et al., 2016; Fuchs et al., 2016).

Third, the data of Study 2 add strength to the early evidence on the importance of a computer-aided program for helping persons in the later stages of the Alzheimer's disease engage in mild physical exercise on their own, presumably: (a) motivated by the stimulation available for their responses and (b) encouraged by the reminders occurring in case of response discontinuity (Kazdin, 2001; Pierce and Cheney, 2008; Letts et al., 2011; Catania, 2012; Halpern, 2012). The same program could also be considered useful for supporting other forms of arm and leg responses and thus extending and varying the exercise opportunities and possibly increasing the beneficial consequences for the participants (e.g., protecting or improving their mobility and mood; Christofoletti et al., 2011; Intlekofer and Cotman, 2013; Farina et al., 2014; Lancioni et al., 2015b; Paillard et al., 2015; Phillips et al., 2015; Bechard et al., 2016). In the absence of such a program, persons like those involved in Study 2 would be generally passive and sedentary (i.e., in a condition entailing reduced levels of direct stimulation) with only limited chances of relying on staff's help. In fact, staff might only rarely have sufficient time to ensure specific, individualized delivery of contingent stimulation and reminders (Williams and Tappen, 2008; Brown et al., 2009; 
Friedman et al., 2009; Lancioni et al., 2009a,b; Wood et al., 2009; Pilotto et al., 2011; Rimmer and Marques, 2012; Perales et al., 2013).

In conclusion, the results of the two studies confirm that relatively simple technology-aided programs might be used profitably for supporting independent (i.e., computer-mediated) verbal engagement/reminiscence and mild physical exercise in persons with Alzheimer's disease. In spite of these encouraging results, some caution may be required in making definite statements about the impact and practical implications of the studies, given that the numbers of participants were fairly small and the research designs and data analyses were fairly unsophisticated. New research efforts are needed to: (a) extend the assessment of the programs with additional participants, thus rectifying a limitation of the present studies and of previous ones in the area; (b) investigate the potential of reminiscence and physical exercise for granting the participants some level of protection against (an opportunity to slow down) their inevitable decline; and (c) seek new technology solutions and additional exercise responses to improve the programs' applicability and

\section{REFERENCES}

Ambrose, C. T. (2012). Neuroangiogenesis: a vascular basis for Alzheimer's disease and cognitive decline during aging. J. Alzheimers Dis. 32, 773-788. doi: 10. 3233/JAD-2012-120067

Astell, A. J., Ellis, M. P., Alm, N., Dye, R., and Gowans, G. (2010a). Stimulating people with dementia to reminisce using personal and generic photographs. Int. J. Comput. Healthc. 1, 177-198. doi: 10.1504/ijcih.2010.037461

Astell, A. J., Ellis, M. P., Bernardi, L., Alm, N., Dye, R., Gowans, G., et al. (2010b). Using a touch screen computer to support relationships between people with dementia and caregivers. Interact. Comput. 22, 267-275. doi: 10.1016/j.intcom. 2010.03.003

Barlow, D. H., Nock, M., and Hersen, M. (2009). Single-Case Experimental Designs. 3rd Edn. New York, NY: Allyn and Bacon

Bechard, A. R., Cacodcar, N., King, M. A., and Lewis, M. H. (2016). How does environmental enrichment reduce repetitive motor behaviors? Neuronal activation and dendritic morphology in the indirect basal ganglia pathway of a mouse model. Behav. Brain Res. 299, 122-131. doi: 10.1016/j.bbr.2015.11.029

Berk, C., Paul, G., and Sabbagh, M. (2014). Investigational drugs in Alzheimer's disease: current progress. Expert. Opin. Investig. Drugs 23, 837-846. doi: 10. 1517/13543784.2014.905542

Bernick, C., Cummings, J., Raman, R., Sun, X., and Aisen, P. (2012). Age and rate of cognitive decline in Alzheimer disease: implications for clinical trials. Arch. Neurol. 69, 901-905. doi: 10.1001/archneurol.2011.3758

Bezzina, C., Verret, L., Halley, H., Dahan, L., and Rampon, C. (2015). Environmental enrichment does not influence hypersynchronous network activity in the Tg2576 mouse model of Alzheimer's disease. Front. Aging Neurosci. 7:178. doi: 10.3389/fnagi.2015.00178

Bharwani, G., Parikh, P. J., Lawhorne, L. W., VanVlymen, E., and Bharwani, M. (2012). Individualized behavior management program for Alzheimer's/dementia residents using behavior-based ergonomic therapies. Am. J. Alzheimers Dis. Other Demen. 27, 188-195. doi: 10. $1177 / 1533317512443869$

Boller, B., Jennings, J. M., Dieudonné, B., Verny, M., and Ergis, A.-M. (2012). Recollection training and transfer effects in Alzheimer's disease: effectiveness of the repetition-lag procedure. Brain Cogn. 78, 169-177. doi: 10.1016/j.bandc. 2011.10.011

Brown, R. I., Schalock, R. L., and Brown, I. (2009). Quality of life: its application to persons with intellectual disabilities and their families-introduction and overview. J. Policy Pract. Intellect. Disabil. 6, 2-6. doi: 10.1111/j.1741-1130. 2008.00202.x friendliness (Kennedy, 2005; Barlow et al., 2009; Subramaniam and Woods, 2012; Hannan, 2014; Saczynski et al., 2014; Wingbermuehle et al., 2014; Bezzina et al., 2015; Freret et al., 2015; Mulfari et al., 2015; Phillips et al., 2015; Bechard et al., 2016; Fuchs et al., 2016). Evaluating the participants' comfortableness with the technology packages adopted and gathering staff and families' opinions about such packages would be essential to design adaptations of the present programs and develop new, successful alternative solutions for applied contexts (Callahan et al., 2008; de Joode et al., 2012, 2013; Robert et al., 2013; Meiland et al., 2014; König et al., 2015).

\section{AUTHOR CONTRIBUTIONS}

NNS, MFO'R, JS and FD'A: Work conception, data acquisition/analysis, and manuscript editing (plus final approval and accountability). CR and KP: Data acquisition/analysis, and manuscript editing (plus final approval and accountability). All authors listed, have made substantial, direct and intellectual contribution to the work, and approved it for publication.

Buchhold, B., Mogoanta, L., Suofu, Y., Hamm, A., Walker, L., Kessler, Ch., et al. (2007). Environmental enrichment improves functional and neuropathological indices following stroke in young and aged rats. Restor. Neurol. Neurosci. 25, 467-484.

Callahan, K., Henson, R., and Cowan, A. K. (2008). Social validation of evidencebased practices in autism by parents, teachers and administrators. J. Autism Dev. Disord. 38, 678-692. doi: 10.1007/s10803-007-0434-9

Catania, A. C. (2012). Learning, 5th Edn. New York, NY: Sloan.

Cavallo, M., Cavanna, A. E., Harciarek, M., Johnston, H., Ostacoli, L., and Angiletta, C. (2013). 'Keep up the good work!': a case study of the effects of a specific cognitive training in Alzheimer's disease. Neurocase 19, 542-552. doi: 10.1080/13554794.2012.701643

Chiang, K.-J., Chu, H., Chang, H.-J., Chung, M.-H., Chen, C.-H., Chiou, H.-Y., et al. (2010). The effects of reminiscence therapy on psychological well-being, depression and loneliness among the institutionalized aged. Int. J. Geriatr. Psychiatry 25, 380-388. doi: 10.1002/gps.2350

Christofoletti, G., Oliani, M. M., Bucken-Gobbi, L. T., Gobbi, S., Beinotti, F., and Stella, F. (2011). Physical activity attenuates neuropsychiatric disturbances and caregiver burden in patients with dementia. Clinics (Sao Paulo) 66, 613-618. doi: 10.1590/s1807-59322011000400015

Crete-Nishihata, M., Baecker, R. M., Massimi, M., Ptak, D., Campigotto, R., Kaufman, L. D., et al. (2012). Reconstructing the past: personal memory technologies are not just personal and not just for memory. Hum. Comput. Interact. 27, 93-123. doi: 10.1080/07370024.2012.656062

de Joode, E. A., van Boxtel, M. P. J., Verhey, F. R., and van Heugten, C. M. (2012). Use of assistive technology in cognitive rehabilitation: exploratory studies of the opinions and expectations of healthcare professionals and potential users. Brain Inj. 26, 1257-1266. doi: 10.3109/02699052.2012.667590

de Joode, E. A., Van Heugten, C. M., Verhey, F. R., and Van Boxtel, M. P. J. (2013). Effectiveness of an electronic cognitive aid in patients with acquired brain injury: a multicentre randomised parallel-group study. Neuropsychol. Rehabil. 23, 133-156. doi: 10.1080/09602011.2012.726632

De Leo, G., Brivio, E., and Sautter, S. (2011). Supporting autobiographical memory in patients with Alzheimer's disease using smart phones. Appl. Neuropsychol. 18, 69-76. doi: 10.1080/09084282.2011.545730

de Vries, K. (2013). Communicating with older people with dementia. Nurs. Older People 25, 30-37. doi: 10.7748/nop2013.05.25.4.30.e429

Eggermont, L. H., Gavett, B. E., Volkers, K. M., Blankevoort, C. G., Scherder, E. J., Jefferson, A. L., et al. (2010). Lower-extremity function in cognitively healthy aging, mild cognitive impairment and Alzheimer's disease. Arch. Phys. Med. Rehabil. 91, 584-588. doi: 10.1016/j.apmr.2009.11.020 
Farina, N., Rusted, J., and Tabet, N. (2014). The effect of exercise interventions on cognitive outcome in Alzheimer's disease: a systematic review. Int. Psychogeriatr. 26, 9-18. doi: 10.1017/S1041610213001385

Ferrero-Arias, J., Goñi-Imízcoz, M., González-Bernal, J., Lara-Ortega, F., da SilvaGonzález, A., and Díez-Lopez, M. (2011). The efficacy of nonpharmacological treatment for dementia-related apathy. Alzheimer Dis. Assoc. Disord. 25, 213-219. doi: 10.1097/WAD.0b013e3182087dbc

Folstein, M., Folstein, S. E., and McHugh, P. R. (1975). "Mini-mental state" a practical method for grading the cognitive state of patients for the clinician. J. Psychiatr. Res. 12, 189-198. doi: 10.1016/0022-3956(75)90026-6

Freret, T., Gaudreau, P., Schumann-Bard, P., Billard, J.-M., and Popa-Wagner, A. (2015). Mechanisms underlying the neuroprotective effect of brain reserve against late life depression. J. Neural Transm. (Vienna) 122, 55-61. doi: 10. 1007/s00702-013-1154-2

Friedman, B., Wamsley, B. R., Liebel, D. V., Saad, Z. B., and Eggert, G. M. (2009). Patient satisfaction, empowerment and health and disability status effects of a disease management-health promotion nurse intervention among medicare beneficiaries with disabilities. Gerontologist 49, 778-792. doi: 10 . 1093/geront/gnp090

Fuchs, F., Cosquer, B., Penazzi, L., Mathis, C., Kelche, C., Majchrzak, M., et al. (2016). Exposure to an enriched environment up to middle age allows preservation of spatial memory capabilities in old age. Behav. Brain Res. 299, 1-5. doi: 10.1016/j.bbr.2015.11.019

Giordano, M., Dominguez, L. J., Vitrano, T., Curatolo, M., Ferlisi, A., Di Prima, A., et al. (2010). Combination of intensive cognitive rehabilitation and donepezil therapy in Alzheimer's disease (AD). Arch. Gerontol. Geriatr. 51, 245-249. doi: 10.1016/j.archger.2009.11.008

Godwin, K. M., Mills, W. L., Anderson, J. A., and Kunik, M. E. (2013). Technology-driven interventions for caregivers of persons with dementia: a systematic review. Am. J. Alzheimers Dis. Other Demen. 28, 216-222. doi: 10. $1177 / 1533317513481091$

Halpern, A. R. (2012). Dementia and music: challenges and future directions. Music Percept. Interdiscip. J. 29, 543-545. doi: 10.1525/mp.2012.29.5.543

Hannan, A. J. (2014). Review: environmental enrichment and brain repair: harnessing the therapeutic effects of cognitive stimulation and physical activity to enhance experience-dependent plasticity. Neuropathol. Appl. Neurobiol. 40, 13-25. doi: 10.1111/nan.12102

Hoffmann, K., Frederiksen, K. S., Sobol, N. A., Beyer, N., Vogel, A., Simonsen, A. H., et al. (2013). Preserving cognition, quality of life, physical health and functional ability in Alzheimer's disease: the effect of physical exercise (ADEX trial): rationale and design. Neuroepidemiology 41, 198-207. doi: 10. 1159/000354632

Huang, S. L., Li, C. M., Yang, C. Y., and Chen, J. J. (2009). Application of reminiscence treatment on older people with dementia: a case study in Pingtung, Taiwan. J. Nurs. Res. 17, 112-119. doi: 10.1097/jnr. 0b013e3181a53f1b

Intlekofer, K. A., and Cotman, C. W. (2013). Exercise counteracts declining hippocampal function in aging and Alzheimer's disease. Neurobiol. Dis. 57, 47-55. doi: 10.1016/j.nbd.2012.06.011

Kazdin, A. E. (2001). Behavior Modification in Applied Settings, 6th Edn. New York, NY: Wadsworth.

Kazdin, A. E. (2011). Single-Case Research Designs: Methods for Clinical and Applied Settings, 2nd Edn. New York, NY: Oxford University Press.

Kennedy, C. (2005). Single Case Designs for Educational Research. New York, NY: Allyn and Bacon.

Kim, S.-Y., Yoo, E.-Y., Jung, M.-Y., Park, S.-H., and Park, J.-H. (2012). A systematic review of the effects of occupational therapy for persons with dementia: a meta-analysis of randomized controlled trials. NeuroRehabilitation 31, 107-115. doi: 10.3233/NRE-2012-0779

König, A., Crispim Junior, C. F., Derreumaux, A., Bensadoun, G., Petit, P. D., Bremond, F., et al. (2015). Validation of an automatic video monitoring system for the detection of instrumental activities of daily living in dementia patients. J. Alzheimers Dis. 44, 675-685. doi: 10.3233/JAD-141767

Kurz, A., and Grimmer, T. (2014). Efficay of memantine hydrochloride once-daily in Alzheimer's disease. Expert Opin. Pharmacother. 15, 1955-1960. doi: 10. 1517/14656566.2014.945907

Kuwahara, N., Yasuda, K., Tetsutani, N., and Morimoto, K. (2010). Remote assistance for people with dementia at home using reminiscence systems and a schedule prompter. Int. J. Comput. Healthc. 1, 126-143. doi: 10.1504/ijcih. 2010.037458

Lancioni, G. E., Perilli, V., Singh, N. N., O’Reilly, M. F., Sigafoos, J., Cassano, G., et al. (2012). Technology-aided pictorial cues to support the performance of daily activities by persons with mild or moderate Alzheimer's disease. Res. Dev. Disabil. 33, 265-273. doi: 10.1016/j.ridd.2011.09.017

Lancioni, G. E., Singh, N. N., O’Reilly, M. F., Green, V. A., Alberti, G., Boccasini, A., et al. (2014a). Automatic feedback to promote safe walking and speech loudness control in persons with multiple disabilities: two single-case studies. Dev. Neurorehabil. 17, 224-231. doi: 10.3109/17518423.2012.749953

Lancioni, G. E., Singh, N. N., O’Reilly, M. F., Sigafoos, J., Ferlisi, G., Zullo, V., et al. (2014b). A computer-aided program for helping patients with moderate Alzheimer's disease engage in verbal reminiscence. Res. Dev. Disabil. 35, 3026-3033. doi: 10.1016/j.ridd.2014.07.047

Lancioni, G. E., Singh, N. N., O’Reilly, M. F., Sigafoos, J., D’Amico, F., Ferlisi, G., et al. (2015a). Patients with moderate Alzheimer's disease engage in verbal reminiscence with the support of a computer-aided program: a pilot study. Front. Aging Neurosci. 7:109. doi: 10.3389/fnagi.2015.00109

Lancioni, G. E., Singh, N. N., O’Reilly, M. F., Sigafoos, J., D’Amico, F., Sasanelli, G., et al. (2015b). Persons with Alzheimer's disease engage in leisure and mild physical activity with the support of technology-aided programs. Res. Dev. Disabil. 37, 55-63. doi: 10.1016/j.ridd.2014.11.004

Lancioni, G. E., Singh, N. N., O’Reilly, M. F., Sigafoos, J., Pangrazio, M. T., Megna, M., et al. (2009a). Persons with moderate Alzheimer's disease improve activities and mood via instruction technology. Am. J. Alzheimers Dis. Other Demen. 24, 246-257. doi: 10.1177/1533317509332627

Lancioni, G., Singh, N., O’Reilly, M., Zonno, N., Flora, A., Cassano, G., et al. (2009b). Persons with mild and moderate Alzheimer's disease use verbalinstruction technology to manage daily activities: effects on performance and mood. Dev. Neurorehabil. 12, 181-190. doi: 10.1080/17518420903 029493

Lancioni, G. E., Singh, N. N., O’Reilly, M. F., Sigafoos, J., Tatulli, E., Rigante, V., et al. (2010). Technology-aided verbal instructions to help persons with mild or moderate Alzheimer's disease perform daily activities. Res. Dev. Disabil. 31, 1240-1250. doi: 10.1016/j.ridd.2010.07.021

Lazar, A., Thompson, H., and Demiris, G. (2014). A systematic review of the use of technology for reminiscence therapy. Health Educ. Behav. 41, 51S-61S. doi: 10. $1177 / 1090198114537067$

Letts, L., Edwards, M., Berenyi, J., Moros, K., O’Neill, C., O’Toole, C., et al. (2011). Using occupations to improve quality of life, health and wellness and client and caregiver satisfaction for people with Alzheimer's disease and related dementias. Am. J. Occup. Ther. 65, 497-504. doi: 10.5014/ajot.2011.002584

Makel, M. C., and Plucker, J. A. (2014). Facts are more important than novelty: replication in the education sciences. Educ. Res. 43, 304-316. doi: 10. 3102/0013189x14545513

Meiland, F. J. M., Hattink, B. J. J., Overmars-Marx, T., de Boer, M. E., Jedlitschka, A., Ebben, P. W. G., et al. (2014). Participation of end users in the design of assistive technology for people with mild to severe cognitive problems: the European Rosetta project. Int. Psychogeriatr. 26, 769-779. doi: 10. 1017/s1041610214000088

Melrose, R. J., Ettenhofer, M. L., Harwood, D., Achamallah, N., Campa, O., Mandelkern, M., et al. (2011). Cerebral metabolism, cognition and functional abilities in Alzheimer disease. J. Geriatr. Psychiatry Neurol. 24, 127-134. doi: 10. $1177 / 0891988711405333$

Mulfari, D., Celesti, A., Villari, M., and Puliafito, A. (2015). Providing assistive technology applications as a service through cloud computing. Assist. Technol. 27, 44-51. doi: 10.1080/10400435.2014.963258

Noguchi, D., Kawano, Y., and Yamanaka, K. (2013). Care staff training in residential homes for managing behavioural and psychological symptoms of dementia based on differential reinforcement procedures of applied behaviour analysis: a process research. Psychogeriatrics 13, 108-117. doi: 10.1111/psyg. 12006

Paillard, T., Rolland, Y., and de Souto Barreto, P. (2015). Protective effects of physical exercise in Alzheimer's disease and Parkinson's disease: a narrative review. J. Clin. Neurol. 11, 212-219. doi: 10.3988/jen.2015.11.3.212

Perales, J., Cosco, T. D., Stephan, B. C. M., Haro, J. M., and Brayne, C. (2013). Health-related quality-of-life instruments for Alzheimer's disease and mixed dementia. Int. Psychogeriatr. 25, 691-706. doi: 10.1017/S1041610212002293 
Perri, R., Monaco, M., Fadda, L., Caltagirone, C., and Carlesimo, G. A. (2014). Neuropsychological correlates of behavioral symptoms in Alzheimer's disease, frontal variant of frontotemporal, subcortical vascular and Lewy body dementias: a comparative study. J. Alzheimers Dis. 39, 669-677. doi: 10. 3233/JAD-131337

Phillips, C., Baktir, M. A., Das, D., Lin, B., and Salehi, A. (2015). The link between physical activity and cognitive dysfunction in Alzheimer disease. Phys. Ther. 95, 1046-1060. doi: 10.2522/ptj.20140212

Pierce, W. D., and Cheney, C. D. (2008). Behavior Analysis and Learning, 4th Edn. New York, NY: Psychology Press.

Pilotto, A., D’Onofrio, G., Benelli, E., Zanesco, A., Cabello, A., Margeli, M. C., et al. (2011). Information and communication technology systems to improve quality of life and safety of Alzheimer's disease patients: a multicenter international survey. J. Alzheimers Dis. 23, 131-141. doi: 10.3233/JAD-2010101164

Rimmer, J. H., and Marques, A. C. (2012). Physical activity for people with disabilities. Lancet 380, 193-195. doi: 10.1016/S0140-6736(12)61028-9

Robert, P. H., Konig, A., Andrieu, S., Bremond, F., Chemin, I., Chung, P. C., et al. (2013). Recommendations for ICT use in Alzheimer's disease assessment: monaco CTAD expert meeting. J. Nutr. Health Aging 17, 653-660. doi: 10. 1007/s12603-013-0046-3

Rolland, Y., Abellan van Kan, G., and Vellas, B. (2008). Physical activity and Alzheimer's disease: from prevention to therapeutic perspectives. J. Am. Med. Dir. Assoc. 9, 390-405. doi: 10.1016/j.jamda.2008.02.007

Saczynski, J. S., Inouye, S. K., Kosar, C., Tommet, D., Marcantonio, E. R., Fong, T., et al. (2014). Cognitive and brain reserve and the risk of postoperative delirium in older patients: analysis of data from a prospective observational study. Lancet Psychiatry 1, 437-443. doi: 10.1016/s2215-0366(14)00009-1

Schecker, M., Pirnay-Dummer, P., Schmidtke, K., Hentrich-Hesse, T., and Borchardt, D. (2013). Cognitive interventions in mild Alzheimer's disease: a therapy-evaluation study on the interaction of medication and cognitive treatment. Dement Geriatr. Cogn. Dis. Extra 3, 301-311. doi: 10. $1159 / 000354190$

Serrani Azcurra, D. J. (2012). A reminiscence program intervention to improve the quality of life of long-term care residents with Alzheimer's disease: a randomized controlled trial. Rev. Bras. Psiquiatr. 34, 422-433. doi: 10.1016/j. rbp.2012.05.008

Siegel, S. E., Castellan, N. J. (1988). Nonparametric Statistics for the Behavioral Sciences, 2nd Edn. New York, NY: McGraw-Hill.

Sikkes, S. A., Pijnenburg, Y. A., Knol, D. L., de Lange-de Klerk, E. S., Scheltens, P., and Uitdehaag, B. M. (2013). Assessment of instrumental activities of daily living in dementia: diagnostic value of the Amsterdam instrumental activities of daily living questionnaire. J. Geriatr. Psychiatry Neurol. 26, 244-250. doi: 10. $1177 / 0891988713509139$
Soto, M. E., Secher, M., Gillette-Guyonnet, S., Abellan van Kan, G., Andrieu, S., Nourhashemi, F., et al. (2012). Weight loss and rapid cognitive decline in community-dwelling patients with Alzheimer's disease. J. Alzheimers Dis. 28, 647-654. doi: 10.3233/JAD-2011-110713

Spalletta, G., Calatagirone, C., Girardi, P., Gianni, W., Casini, A. R., and Palmer, K. (2012). The role of persistent and incident major depression on rate of cognitive deterioration in newly diagnosed Alzheimer's disease patients. Psychiatry Res. 198, 263-268. doi: 10.1016/j.psychres.2011.11.018

Subramaniam, P., and Woods, B. (2012). The impact of individual reminiscence therapy for people with dementia: systematic review. Expert. Rev. Neurother. 12, 545-555. doi: 10.1586/ern.12.35

Tifratene, K., Sakarovitch, C., Rouis, A., Pradier, C., and Robert, P. (2014). Mild cognitive impairment and anti-Alzheimer disease medication: a cross sectional study of the French National Alzheimer Databank (BNA). J. Alzheimers Dis. 38, 541-549. doi: 10.3233/JAD-131103

Williams, C. L., and Tappen, R. M. (2008). Exercise training for depressed older adults with Alzheimer's disease. Aging Ment. Health 12, 72-80. doi: 10. $1080 / 13607860701529932$

Wilson, R. S., Segawa, E., Boyle, P. A., Anagnos, S. E., Hizel, L. P., and Bennett, D. A. (2012). The natural history of cognitive decline in Alzheimer's disease. Psychol. Aging 27, 1008-1017. doi: 10.1037/a0029857

Wingbermuehle, C., Bryer, D., Berg-Weger, M., Tumosa, N., McGillick, J., Rodriguez, C., et al. (2014). Baseball reminiscence league: a model for supporting persons with dementia. J. Am. Med. Dir. Assoc. 15, 85-89. doi: 10. 1016/j.jamda.2013.11.006

Wood, W., Womack, J., and Hooper, B. (2009). Dying of boredom: an exploratory case study of time use, apparent affect and routine activity situations on two Alzheimer's special care units. Am. J. Occup. Ther. 63, 337-350. doi: 10. 5014/ajot.63.3.337

Yasuda, K., Kuwahara, N., and Morimoto, K. (2009). Remote reminiscence talking and scheduling prompter for individuals with dementia using video phone. Lect. Notes Comput. Sci. 5614, 429-438. doi: 10.1007/978-3-642-02707-9_49

Conflict of Interest Statement: The authors declare that the research was conducted in the absence of any commercial or financial relationships that could be construed as a potential conflict of interest.

Copyright (C) 2016 Lancioni, Singh, O'Reilly, Sigafoos, D'Amico, Renna and Pinto. This is an open-access article distributed under the terms of the Creative Commons Attribution License (CC BY). The use, distribution and reproduction in other forums is permitted, provided the original author(s) or licensor are credited and that the original publication in this journal is cited, in accordance with accepted academic practice. No use, distribution or reproduction is permitted which does not comply with these terms. 